Research Article

\title{
A Study on the Prescription Pattern of Antimicrobial Agents Used in the Treatment of Infectious Disease
}

\author{
Mahadevamma Lingaiah ${ }^{1 *}$, Dr. Mehraj Khan ${ }^{2}$, Dr. Amjadkhan Asadkan Pathan ${ }^{3}$, Dr. Sherin Shaji ${ }^{4}$ \\ $1^{*}$ Research Scholar, Shri J.J.T., University, Jhunjhunu, Rajasthan, India. \\ ${ }^{2}$ Assistant Professor, Shri Jagdishprasad Jhabarmal Tibrewala University, Rajasthan-333001, India. \\ ${ }^{3}$ Professor, Shri Jagdishprasad Jhabarmal Tibrewala University, Rajasthan - 333001, India. \\ ${ }^{4}$ Assistant Professor, Department of Pharmacy Practice, East West College of Pharmacy, Bangalore-560091, India. \\ *Corresponding author's E-mail: mahadevammalingaiah11@gmail.com
}

Received: 10-10-2021; Revised: 26-11-2021; Accepted: 05-12-2021; Published on: 20-12-2021.

\section{ABSTRACT}

Antibiotics are anti-infective agents produced from natural sources, whereas antimicrobial agents are generated through chemical synthesis. It was a prospective and observational study and was conducted in the medicine, OBG, and urology departments in Sagar Hospitals. The study was conducted over a period of 18 to 20 months. Among 542 participants, $325(60 \%)$ were males, while 217 $(40 \%)$ were females. The frequency of patients surviving different hospital departments was $416(76.6 \%)$, and they survived the medicine department. Moreover, the urology department had $80(14.8 \%)$ patient visits, while in the obstetrics and gynaecology departments, only $46(8.5 \%)$ patients visited. It was found that the percentage and order of various micro-organisms isolated as Neisseria meningitides $20(3.7 \%)$ and a lesser number of organisms were found in K. Pneumonia 01 (0.2\%), respectively. The cephalosporin class of drugs is commonly prescribed in empirical and prophylactic therapy because they are more effective in infectious diseases Furthermore, 36 patients out of 542 had drug interactions; quinoline derivatives, such as Ciprofloxacin, typically have a higher number of drug interactions. Among 542 patients, 38 had severe drug reactions in that most of the reactions were dermatological reactions caused by cephalosporin drugs. Most of our physicians prescribed based on patient characteristics and behaviors, and the recovery rate was also good. In our study, we observed common outcomes of DIs, such as increased theophylline toxicity and digoxin toxicity, increased laboratory values, and also reduced some drugs' effectiveness. Correlations of drug and disease characteristics were found more in ciprofloxacin drugs.

Keywords: antibiotics, prospective, drug interaction, Prescription Pattern.

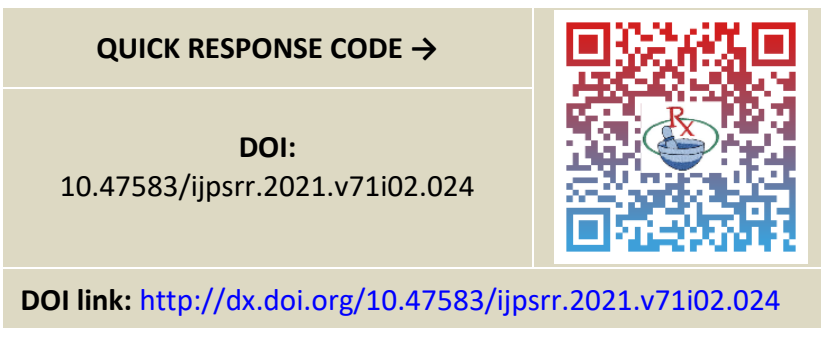

\section{INTRODUCTION}

nfection is the invasion of an organism body's tissue due to foreign organism that causes diseases, it is caused due to their multiplication, and the reaction due to infectious agents and toxins they produce on the host's tissues. ${ }^{1}$ The foreign organisms may be bacteria, viruses, fungi and parasites. The entry of pathogen into the host's body generally occurs through mucosa in the orifices like of the oral cavity, nose, eyes, genitalia, anus or through the open wounds. Once the pathogen enters the host body, it avoids the body's immune responses and uses the body's resources to replicate and spread the infection. Normally, they are harmless but under certain condition they cause disease. The illness caused or resulted due infection is called as infectious diseases. Infectious disease is also known as communicable or transmissible diseases. Individuals having weak or suppressed immune system are more susceptible or prone to cause the diseases. ${ }^{2}$
Infective agents treat infection by suppressing or destroying the causative microorganisms' bacteria, mycobacterium, fungi, protozoa or viruses. Anti-infective agents derived from natural substances are called antibiotics; those produced from synthetic substance are called antimicrobial agents. ${ }^{3}$

Antibiotics are medications that treat bacterial infections. Cephalosporin's are a group of antibiotics derived from the mould Acremonium which was previously called as Cephalosporium. Cephalosporin's are a type of antibiotic that can be taken orally for simple infection or injected into a vein (intravenous injection) for severe infection. Cephalosporin are commonly used group of antibiotics in hospitals and healthcare facilities around the world. In the developed countries through the use of older cephalosporin is declining, that of the newer generation has increased. Cephalosporins are bactericidal beta-lactam antibiotics. Cephalosporins have a broader spectrum of activity therefore are more stable to many bacterial beta lactamases. ${ }^{4}$

Cephalosporins are used during the surgeries. As it have antimicrobial property, it can lower the incidence of infection after certain operations, and thus it is used as prophylaxis to reduce morbidity, hospital stay, antibiotic usage and mortality due to sepsis or infections. The antimicrobial prophylaxis is used before the operation. 
Cephalosporins are used as they offer fewer allergic reactions than other antibiotics. There is an increase in the occurrence of known resistant pathogens and as well as emergence of newly resistant bacteria, such as Enterococcus faecium, Staphylococcus aureus, Clostridium difficile, Klebsiella pneumoniae, Acinetobacterbaumanii, Pseudomonas aeruginosa and Enterobacteriaceae. ${ }^{5}$

Inappropriate prescribing leading to serious morbidity and mortality, in childhood infections or chronic diseases like hypertension, diabetes, epilepsy, and mental disorders are being treated. It also represents a waste of antimicrobial resources, public health hazard by contributing to increased bacterial resistance. An over willingness prescribing leads to failure of the treatment. ${ }^{6}$

The medical audit improves the standards of medical treatment at all levels of health care delivery system. So, the medical audit is necessary for rationality. The study of prescribing pattern is a component of medical audit which seeks monitoring, evaluation and necessary modifications in the prescribing practices of the prescribers to achieve rational and cost effective medical care. It is necessary to define the prescribing pattern and to identify the irrational prescribing habits to drive a remedial message to the prescribers. $^{7}$

Drug-Drug interactions (DDIs) are changes in a drug's effects caused by another drug taken during the same time period. ${ }^{8}$

Most interactions involving antibiotics are pharmacokinetic ones and occur when one drug alters the absorption, distribution or elimination of another. Antibiotics may be the targets of such interactions, especially when their absorption from the gastrointestinal tract is affected. The potential for interaction between antibiotics and other drugs needs to be continually borne in mind, especially with the increasing trend towards polypharmacy such that many patients are taking four or five different agents. In these circumstances even short courses of antibiotics may have serious consequences. ${ }^{9}$

In health-care system, Pharmacists have duty to play major role in antibiotic use, infection prevention and control programs. Through clinical initiative center on appropriate antibiotic use and participation on relevant interdisciplinary work groups and committees within the health system, pharmacists are required to engage in antimicrobial usage, infection prevention, and control activities. ${ }^{12}$

\section{METHODOLOGY}

\section{Study site}

This study was conducted at Sagar Hospital, Bengaluru. It is a 300-bed multispecialty tertiary care teaching hospital. This hospital provides primary and specialized health care facilities to people in and around Bengalrur rural and urban areas. The hospital has various departments like Medicine, Pediatrics, Psychiatry, Obstetrics and Gynecology, Surgery, Orthopedics, Ophthalmology, ENT, Radiology, Skin and
STDs, and Community Medicine. Approximately 200-300 patients are being treated every day. Patients are usually referred to this hospital by general practitioners.

\section{Study design}

A Prospective and Observational Study

\section{Sample}

Patients were enrolled from the Medicine, OBG, and Urology departments at Sagar Hospital. Patients who satisfied the study criteria and agreed to participate in this study.

\section{Study period}

The study was conducted over a period of 18 to 20 months, starting in 2017 and ending in 2019.

\section{Ethical approval}

Ethical committee clearance has been obtained from the institutional ethical committee of Sagar Hospital.

\section{Study criteria}

\section{Inclusion Criteria}

- A patient diagnosed with infectious diseases

- Patients should be prescribed with any antimicrobial agents.

- In-patient admitted for a period of more than 24 hours.

\section{Exclusion criteria}

- Pregnant and lactating women

- $\quad$ Patients who are under the age of 18

\section{Source of information}

- Patient's case notes

- Medication or treatment chart

- Laboratory report

- Prescriptions

- Personal interactions with patients

\section{Study Procedure}

\section{Methods of Data Collection}

Prescriptions of the out patients and the treatment charts of the inpatients were reviewed prospectively for the treatment of the UTI in different departments.

\section{Determination of Prescription Pattern}

A Prospective study was conducted to collect the data pertaining to the study of the drug utilization pattern of antimicrobial for the treatment of infectious diseases in the General Medicine, OBG and Urology departments of Sagar hospital. After the diagnosis was confirmed necessary baseline information such as details like age, sex, patient educational background, socio demographic, 
date of admission, date of discharge, the occupation details was also be collected. To assess the prescription pattern of drugs, they were categorized with the class of individual antimicrobial drugs and therapeutic data such as name of drugs, dose, route of administration and duration. To assess the variables by using parameters like culture sensitivity test, leukocyte count, white blood cell (WBC) count, GRBS/ HbA1c, serum creatinine, USG abdomen/ CT abdomen and Urine routine. Prophylactic therapy was assessed using subjective evidence such as chief complaint of the patients and empirical therapy was be assessed with the help of laboratory variables. To assess the drug interaction by using nature of severity like major, moderate and minor and drug interactions were identified by using the software MICROMEDEX and the standard text books (Martindale, Stockly). The potential outcome of the interaction was assessed based on literature patient interview and discussion with clinician. Those interactions which were assumed to have happened in the patients were evaluated for various parameters. Nature of interaction were evaluated with regard to onset, severity, documentation was evaluated. Data was assessed to evaluate the individual drug and drug class involved in interactions. Antimicrobial agents induced adverse drug reactions was also be documented in a suitable designed data collection form and the follow - ups was also be documented until discharge. The results of the study was analysed with suitable statistical tool.

\section{Criteria For Evaluation}

\section{Criteria for Severity}

The potential severity of the interaction is important in assessing the risks versus

benefits of therapeutic alternatives. With appropriate dosage adjustments or modification of the administration schedule. The negative effects of most interactions can be avoided.

(i) Major interactions may be life-threatening, or intoxication or permanent damage may be induced. Normally, these drugs should not be administered together.

(ii) Moderate interactions frequently cause therapeutic difficulties, but the combinations may be administered if the patient is carefully monitored (laboratory parameters, for example quick value, or clinical symptoms).

(iii) Minor interactions may cause increased or reduced effects or interactions only concerning a certain subgroup (for example patients with renal or hepatic failure, slow acetylizers).

\section{Criteria for Onset}

How rapidly the clinical effects of an interactions can occur determines the urgency with which preventive measure should be instituted to avoid the consequences of the interaction.

\section{Two levels of onset are used}

\section{Rapid}

The effects will be evident within 24 hours of administrations of the interacting drug. Immediate action is necessary to avoid the effects of interactions

\section{Delayed}

The effect will not be evident until the interacting drug is administered for a period of days or weeks. Immediate action is not required.

\section{Statistical Methods}

Descriptive and inferential statistical analysis has been carried out in the present study. Results on continuous measurements are presented on Mean \pm SD (Min-Max) and results on categorical measurements are presented in Number (\%). Significance is assessed at $5 \%$ level of significance. The following assumptions on data is made,

\section{Assumptions}

1.Dependent variables should be normally distributed, 2.Samples drawn from the population should be random, Cases of the samples should be independent Chi-square/ Fisher Exact test has been used to find the significance of study parameters on categorical scale between two or more groups, Non-parametric setting for Qualitative data analysis. Fisher exact test used when cell samples are very small.

\section{Significant figures}

+ Suggestive significance ( $P$ value: $0.05<P<0.10)$

* Moderately significant ( $P$ value: $0.01<P \leq 0.05$ )

** Strongly significant ( $\mathrm{P}$ value: $\mathrm{P} \leq 0.01)$

\section{Statistical software}

The Statistical software namely SPSS 22.0, and R environment ver.3.2.2 were used for the analysis of the data and Microsoft word and Excel have been used to generate graphs, tables etc.

\section{RESULTS AND DISCUSSION}

Table 1: Gender distribution of patients studied.

\begin{tabular}{|c|c|c|}
\hline Gender & No. of patients & Percentage \% \\
\hline Female & 217 & 40.0 \\
\hline Male & 325 & 60.0 \\
\hline Total & $\mathbf{5 4 2}$ & $\mathbf{1 0 0 . 0}$ \\
\hline
\end{tabular}

Table 01 shows the distribution of participants according to their gender. Of 542 participants, 325(60\%) were males while 217 (40\%) females. 


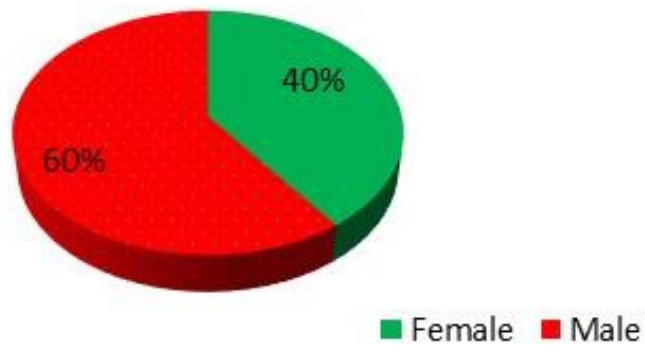

Gender

Figure 1: Gender distribution of patients studied.

Table 2: Age distribution of patients studied.

\begin{tabular}{|c|c|c|}
\hline Age in years & No. of patients & Percentage \% \\
\hline $18-20$ & 9 & 1.7 \\
\hline $21-30$ & 71 & 13.1 \\
\hline $31-40$ & 82 & 15.1 \\
\hline $41-50$ & 81 & 14.9 \\
\hline $51-60$ & 72 & 13.3 \\
\hline $61-70$ & 132 & 24.4 \\
\hline $71-80$ & 60 & 11.1 \\
\hline $81-90$ & 32 & 5.9 \\
\hline$>90$ & 03 & 0.6 \\
\hline Total & $\mathbf{5 4 2}$ & 100.0 \\
\hline
\end{tabular}

Mean \pm SD: $53.17 \pm 18.33$

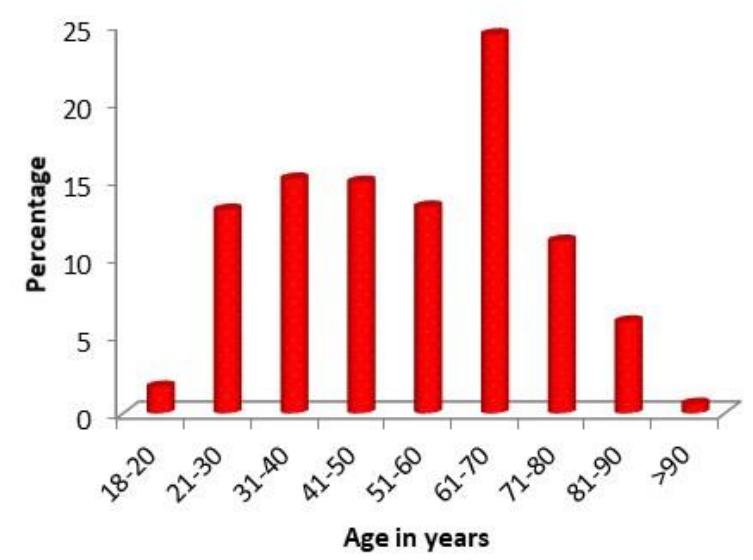

Figure 2: Age distribution of patients studied.

The distribution of the patients according to their age is depicted in table 02 . Majority of the patients $(n=132$, $24.4 \%$ ) belongs to $61-70$-year age group. Age group 31-40 year and 41-50 year follows the next leading group with 82 (15.1\%) and 81 (14.9\%) patients, respectively. In age group 51-60 year, there were $72(13.3 \%)$ patients while 71 (13.1\%) belong to 21-30-year age group. Age group 71-80 year and $81-90$ year are the next leading group with 60 (11.1\%) and 32 (5.9\%) of patients, respectively. In age group 18-20 year, 09 (1.7\%) of patients were included. Only $03(0.6 \%)$ of patients belong to above 90 -year age a group. Average age group of the study population was found to be 53.17 with a standard deviation of \pm 18.33 .

Table 3: Department-Frequency distribution of patients studied.

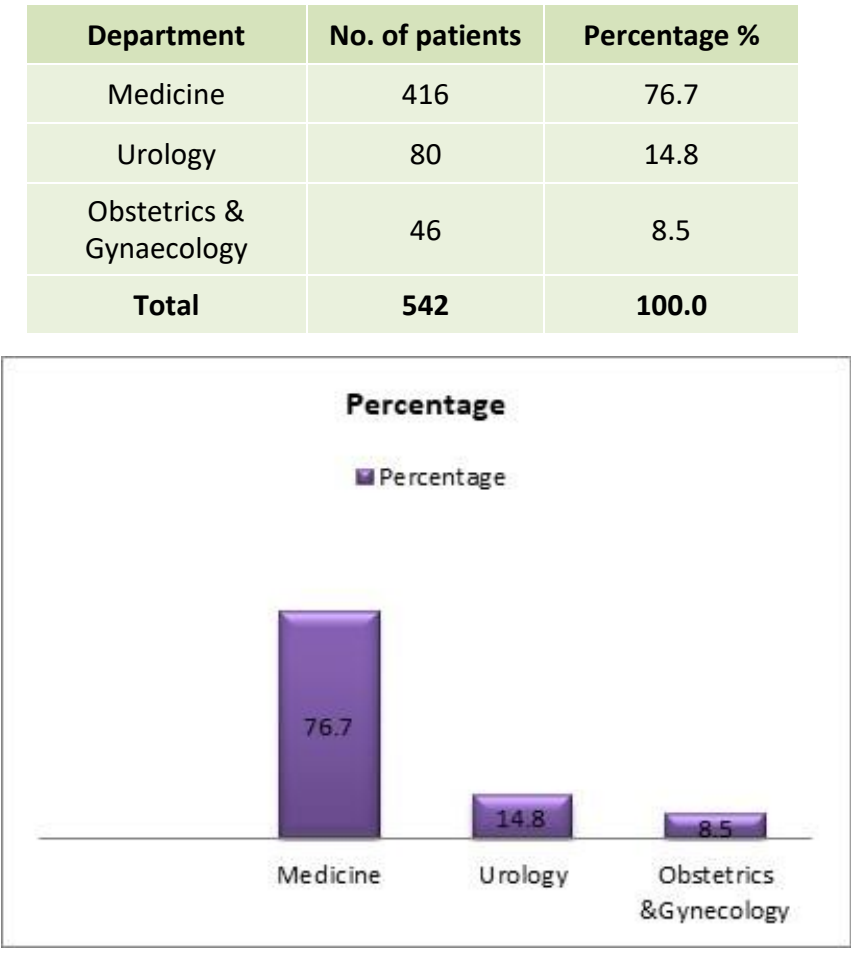

Figure 3: Department-Frequency distribution of patients studied.

The frequency of patients visisted different hospital departements is shown in table 03. Out of 542 patients, most i.e., 416 (76.6\%) visisted medicine department. Urology department had $80(14.8 \%)$ patient visits while in Obsterics and Gynaecology department, only 46 (8.5\%) of patients visisted.

Table 4: Microbial culture sensitivity test-Frequency distribution of patients studied

\begin{tabular}{|c|c|c|}
\hline $\begin{array}{l}\text { Microbial culture } \\
\text { sensitivity test }\end{array}$ & $\begin{array}{l}\text { No. of patients } \\
(n=542)\end{array}$ & $\begin{array}{c}\text { Percentage } \\
\%\end{array}$ \\
\hline No pathogens & 471 & 86.9 \\
\hline Pathogens & 71 & 13.1 \\
\hline - $\quad$ Neisseria meningitidis & 20 & 3.7 \\
\hline - E. Coli & 17 & 3.1 \\
\hline - $\quad$ Cytomegalovirus - & 11 & 2.0 \\
\hline - Unspecified & 10 & 1.8 \\
\hline - Clostridium difficile & 07 & 1.3 \\
\hline - $\quad$ S. Pneumonia & 03 & 0.6 \\
\hline - $\quad$ K. Pneumonia & 01 & 0.2 \\
\hline - No aerobic growth & 01 & 0.2 \\
\hline - $\quad$ Streptococcus & 01 & 0.2 \\
\hline
\end{tabular}




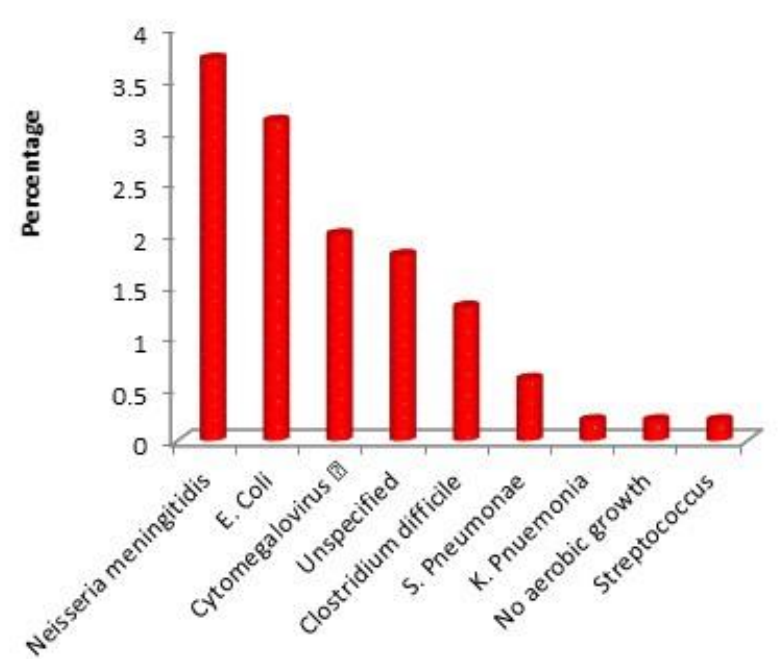

Microbial culture sensitivity test

Figure 4: Microbial culture sensitivity test-Frequency distribution of patients studied.

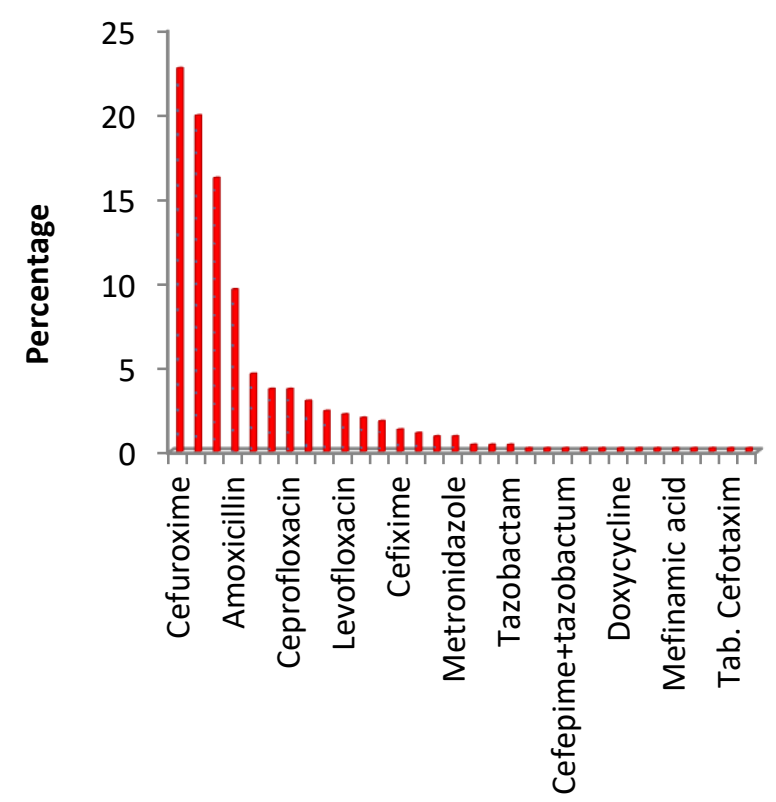

Microbial culture sensitivity test

Figure 5: Microbial culture sensitivity test-Frequency distribution of patients studied.

Table 04 shows frequency distrivution of patients according to microbial culture sensitivity test. Of 542 participants, 471 (86.9\%) had no pathogens while only 71 (13.1\%) of them had pathogens. Most identifed pathogens are Neisserias meningitis, E. coli and Cytomegalovirus with $20(3.7 \%), 17$ (3.1\%) and 11 (2.0\%), respectively. Among 10 $(1.8 \%)$ patients, the pathogen was not able to be clearly specified. Clostridium difficle was identified in 07 (1.3\%) patients and S. pneumoniae was found in $03(0.6 \%)$ patient cultures. K. pneumonia, streptococcus and no aerobic growth was found in 01 (0.2\%) patient each.
Table 5: Antibiotic drug name-Frequency distribution of patients studied

\begin{tabular}{|c|c|c|}
\hline Antibiotic drug name & $\begin{array}{c}\text { No. of } \\
\text { patients }\end{array}$ & $\begin{array}{c}\text { Percentage } \\
\%\end{array}$ \\
\hline 1. Cefuroxime & 123 & 22.7 \\
\hline 2. Cefepime & 108 & 19.9 \\
\hline 3. Ceftriaxone & 88 & 16.2 \\
\hline 4. Amoxicillin & 52 & 9.6 \\
\hline 5. Cefperazone+ Sulbactam & 25 & 4.6 \\
\hline $\begin{array}{l}\text { 6. Cefperazone+Sulbactam, } \\
\text { Azithromycin }\end{array}$ & 20 & 3.7 \\
\hline 7. Ciprofloxacin & 20 & 3.7 \\
\hline 8. Piperacillin+Tazobactam & 16 & 3.0 \\
\hline 9. Cefotaxime & 13 & 2.4 \\
\hline 10. Levofloxacin & 12 & 2.2 \\
\hline 11. Meropenem & 11 & 2.0 \\
\hline 12. Azithromycin & 10 & 1.8 \\
\hline 13. Cefixime & 07 & 1.3 \\
\hline 14. Gentamycin & 06 & 1.1 \\
\hline 15. Cefazolin & 05 & 0.9 \\
\hline 16. Metronidazole & 05 & 0.9 \\
\hline 17. Amikacin & 02 & 0.4 \\
\hline 18. Ofloxacin & 02 & 0.4 \\
\hline 19. Tazobactam & 02 & 0.4 \\
\hline 20. Albendazole & 01 & 0.2 \\
\hline 21. Cefepime & 01 & 0.2 \\
\hline 22. Cefepime+ Tazobactam & 01 & 0.2 \\
\hline 23. Cefepime & 01 & 0.2 \\
\hline 24. Ceftazidime & 01 & 0.2 \\
\hline 25. Doxycycline & 01 & 0.2 \\
\hline 26. Ertapenem & 01 & 0.2 \\
\hline $\begin{array}{l}\text { 27. Imipenem, Norfloxacin, } \\
\text { Ceftriaxone }\end{array}$ & 01 & 0.2 \\
\hline 28. Mefenamic acid & 01 & 0.2 \\
\hline 29. Moxifloxacin & 01 & 0.2 \\
\hline 30. Rifampicin & 01 & 0.2 \\
\hline 31. Cefotaxime & 01 & 0.2 \\
\hline 32. Tigecycline & 01 & 0.2 \\
\hline $\begin{array}{l}\text { 33. Trimethoprim,Tobramycin } \\
\text {,Amikacin,Levofloxacin }\end{array}$ & 01 & 0.2 \\
\hline 34. Vancomycin & 01 & 0.2 \\
\hline Total & 542 & 100.0 \\
\hline
\end{tabular}

Table 05 shows the distribution of various antibiotics given to the study population. Cefuroxime, Cefepime and Ceftriaxone was prescribed to 123 (22.7\%), 108 (19.9) and $88(1602 \%)$, respectively. Amoxicillin was advised to 52 (906\%) of the patients while Cefoperazone+ Sulbactam was given to $25(4.6 \%)$ of patients. Cefoperazone, 
Sulbactam, Azithromycin combined, and Ciprofloxacin was given to $20(3.7 \%)$ each. Piperacillin + tazobactam fixed dose regimen was advised to $16(3.0 \%)$ of the patients. Cefotaxime and levofloxacin were given to $13(2.4 \%)$ and $12(2.2 \%)$, respectively. Meropenem was given to $11(2.0 \%)$ patients and Azithromycin was given to 10 (2.8\%) patients. Cefixime and Gentamycin was prescribed to 07 (1.3\%) patients and $06(1.1 \%)$ patients, respectively. Each Cefazoline and Metronidazole was given to 05 (0.9\%) patients. Amikacin, Ofloxacin and tazobactam were given to $02(0.4 \%)$ patients, respectively. Albendazole, Cefepime, Cefepime + tazobactam, Cefepime, Ceftazidime, Doxycycline, Ertapenem, Mefenamic acid, Moxifloxacin, Rifampicin, Tab. Cefotaxime, Tigecycline, Vancomycin each were given to $01(0.2 \%)$ patient. Combined therapy with Imipenem, norfloxacin, ceftriaxone, and Trimethoprim, Tobramycin, Amikacin, Levofloxacin each were advised to 01 (0.2\%) patient.

Table 6: Antimicrobial Agents-Frequency distribution of patients studied

\begin{tabular}{|c|c|c|}
\hline Antimicrobial agents & No. of patients & Percentage \% \\
\hline $\begin{array}{c}\text { Cephalosporin 3rd } \\
\text { Generation }\end{array}$ & 273 & 50.4 \\
\hline 2nd Generation & 131 & 24.2 \\
\hline Penicillin & 48 & 8.9 \\
\hline Fluoroquinolones & 28 & 5.2 \\
\hline B lactam + Penicillin & 13 & 2.4 \\
\hline Macrolide & 10 & 1.8 \\
\hline Aminoglycosides & 06 & 1.1 \\
\hline Carbapenems & 05 & 0.9 \\
\hline Glycopeptide & 05 & 0.9 \\
\hline Lincosamide & 05 & 0.9 \\
\hline Anti-amoebic & 04 & 0.7 \\
\hline Antifungal & 03 & 0.6 \\
\hline Sulfonamides & 02 & 0.4 \\
\hline Quinolones & 02 & 0.4 \\
\hline Anthelmintic & 01 & 0.2 \\
\hline Anti-protozoal & 01 & 0.2 \\
\hline Antitubercular agent & 01 & 0.2 \\
\hline Carbapenem antibiotic & 01 & 0.2 \\
\hline $\begin{array}{c}\text { Carbapenem, } \\
\text { Glycopeptide, Quinolones }\end{array}$ & 01 & 0.2 \\
\hline Carbapenem, Macrolide & 01 & 0.2 \\
\hline Tetracycline & 01 & 0.2 \\
\hline Total & 542 & 100.0 \\
\hline
\end{tabular}

Table 06 shows the frequency of antimicrobial agents given to the study population. Out of 542 patients, 273 (50.4\%) were given Cephalosporin 3rd Generation agents, 131 (24.2\%) were given Cephalosporin 2nd Generation and 48 (8.9\%) were given Penicillin. Fluoroquinolones were prescribed to $28(5.2 \%)$ patients and Beta-lactam +Penicillin combination was given to 13 (2.4\%). Agents from Macrolide class were given to 10 (1.8\%) patients, while from Aminoglycosides were given to 06 (1.1\%) patients. Agents from Carbapenem, Glycopeptide and Lincosamideeach were given to $05(0.9 \%)$ patients. Antiamoebic and Antifungal drugs were prescribed to $0(0.7 \%)$ and $03(0.6 \%)$ patients, respectively. Sulfonamides and Quinolones each were advised to 02 patients $(0.4 \%)$, while Anthelminthic, Anti-protozoal, Antitubercular, Carbapenem -macrolide, Carbapenem-glycopeptidequinolones, Carbapenem antibiotic and Tetracycline agents each were prescribed to $01(0.2 \%)$ patients.

Table 7: Prophylactic therapy

\begin{tabular}{|c|c|c|}
\hline Prophylactic therapy & No. of patients & Percentage \% \\
\hline Inj. Cefuroxime & 190 & 35.1 \\
\hline Inj. Ceftriaxone & 128 & 23.6 \\
\hline $\begin{array}{l}\text { Inj. Amoxicillin + } \\
\text { Clavulanic acid }\end{array}$ & 89 & 16.4 \\
\hline $\begin{array}{l}\text { Inj. Cefoperazone + } \\
\text { Sulbactam }\end{array}$ & 70 & 12.9 \\
\hline Inj. Cefotaxime & 14 & 2.6 \\
\hline Inj. Meropenem & 06 & 1.1 \\
\hline Inj. Gentamicin & 06 & 1.1 \\
\hline Inj. Cefazolin & 05 & 0.9 \\
\hline $\begin{array}{l}\text { Inj. Piperacillin + } \\
\text { Tazobactam }\end{array}$ & 04 & 0.7 \\
\hline Inj. Amikacin & 03 & 0.6 \\
\hline Inj. Cefepime & 02 & 0.4 \\
\hline Inj. Cefixime & 02 & 0.4 \\
\hline $\begin{array}{l}\text { Inj. Cefoperazone + } \\
\text { Sulbactam }\end{array}$ & 02 & 0.4 \\
\hline Levofloxacin & 02 & 0.4 \\
\hline Amoxicillin & 01 & 0.2 \\
\hline Ceftazidime & 01 & 0.2 \\
\hline Cefuroxime & 01 & 0.2 \\
\hline Clarithromycin & 01 & 0.2 \\
\hline Clindamycin & 01 & 0.2 \\
\hline Doxycycline & 01 & 0.2 \\
\hline Inj. Cefpodoxime & 01 & 0.2 \\
\hline Inj. Ciprofloxacin & 01 & 0.2 \\
\hline Inj. Clindamycin & 01 & 0.2 \\
\hline Isoniazid & 01 & 0.2 \\
\hline Itraconazole & 01 & 0.2 \\
\hline Metronidazole & 01 & 0.2 \\
\hline Moxifloxacin & 01 & 0.2 \\
\hline Tab. Cefixime & 01 & 0.2 \\
\hline Tab. Cefixime & 01 & 0.2 \\
\hline Tab. Cefpodoxime & 01 & 0.2 \\
\hline Tab. Cefuroxime & 01 & 0.2 \\
\hline Tab. Cefuroxime & 01 & 0.2 \\
\hline Vancomycin & 01 & 0.2 \\
\hline Total & 542 & 100.0 \\
\hline
\end{tabular}




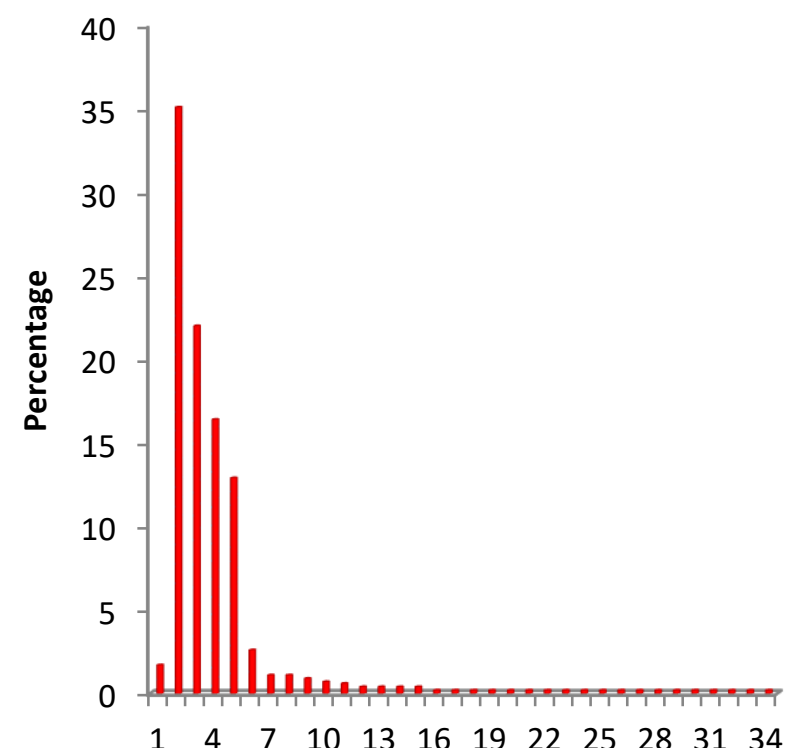

\section{Prophylactic therapy}

Figure 6: Prophylactic therapy

In Table 07. Inj Cefuroxime and Injection. Ceftriaxone was given to 190 (35.1\%) and 128 (23.6\%) patients, respectively. Inj. Amoxicillin + Clavulanic acid and Inj. Cefoperazone + Sulbactam were given to 89 (16.4\%) and $70(12.9 \%)$ patients. Inj. Cefotaxime was administered to 14 (2.6\%) patients. Inj. Meropenem and Inj. Gentamicin each was given to 06 patients (1.1\%). Inj. Cefazolin was given to 05 (0.9\%) patients and Inj. Piperacillin+Tazobactam was given to $04(0.7 \%)$ patients. Inj. Amikacin was given to $03(0.6 \%)$ patients. Inj. Cefpirome + Sulbactam, Inj. Cefepime, Inj. Cefixime and Levofloxacin, each was given to $02(0.4 \%)$ patients. Amoxicillin, Ceftazidime, Cefuroxime, Clarithromycin, Doxycycline, Inj. Cefpodoxime, Inj. Ciprofloxacin, Inj. Clindamycin, Isoniazid, Itraconazole, Metronidazole, Moxifloxacin, Moxifloxacin, Tab. Cefixime, Tab. Cefixime, Tab. Cefpodoxime, Tab. Cefuroxime. Cefuroxime, Vancomycin each was given to 01 patient $(0.2 \%)$.

Table 08 shows the frequency of various antimicrobials used as empirical therapy in the study population. Inj. Cefpirome + Sulbactam was given to 190 patients (35.1\%). Inj. Ceftriaxone was administered as empirical therapy to 120 (22.1\%) patients. Inj. Amikacin was given to 86 (15.9\%) patients and Inj. Cefoperazone + Sulbactam was given to 77 (14.2\%) patients. Tab. Amoxicillin + Clavulanic acid and Tab. Cefuroxime. Ceftriaxone was given to $10(1.8 \%)$ and 09 (1.7\%) patients, respectively. Tab. Cefazolin and Tab. Cefixime each was given to $06(1.1 \%)$ patients, while Inj. Meropenem and Cefuroxime each was given to 05 (0.9\%) patients. Inj. Piperacillin + Tazobactam was given to 04 $(0.7 \%)$ patients and Inj. Cefotaxime was given to $03(0.6 \%)$ patients. Amoxicillin, Ceftazidime, Cefuroxime, Clarithromycin, Clindamycin, Doxycycline, Inj. Cefepime, Inj. Linezolid, Isoniazid, Itraconazole, Metronidazole, Moxifloxacin, Tab. Cefixime + Inj. Ceftriaxone, Tab.
Ceftriaxone and Vancomycin was given to $01(0.2 \%)$ patient.

Table 8: Empirical therapy

\begin{tabular}{|c|c|c|}
\hline Empirical therapy & No. of patients & $\begin{array}{c}\text { Percentage } \\
\%\end{array}$ \\
\hline Inj. Cefpirome + Sulbactam & 190 & 35.1 \\
\hline Inj. Ceftriaxone & 120 & 22.1 \\
\hline Inj. Amikacin & 86 & 15.9 \\
\hline $\begin{array}{l}\text { Inj. Cefoperazone + } \\
\text { Sulbactam }\end{array}$ & 77 & 14.2 \\
\hline $\begin{array}{l}\text { Tab. Amoxicillin + } \\
\text { Clavulanic acid }\end{array}$ & 10 & 1.8 \\
\hline $\begin{array}{l}\text { Tab. Cefuroxime Inj. } \\
\text { Ceftriaxone }\end{array}$ & 09 & 1.7 \\
\hline Inj. Cefazolin & 06 & 1.1 \\
\hline Tab. Cefixime & 06 & 1.1 \\
\hline Inj. Meropenem & 05 & 0.9 \\
\hline Tab. Cefuroxime & 05 & 0.9 \\
\hline $\begin{array}{l}\text { Inj. Piperacillin + } \\
\text { Tazobactam }\end{array}$ & 04 & 0.7 \\
\hline Inj. Cefotaxime & 03 & 0.6 \\
\hline Inj. Cefixime & 02 & 0.4 \\
\hline Levofloxacin & 02 & 0.4 \\
\hline Tab. Cefixime & 02 & 0.4 \\
\hline Amoxicillin & 01 & 0.2 \\
\hline Ceftazidime & 01 & 0.2 \\
\hline Cefuroxime & 01 & 0.2 \\
\hline Clarithromycin & 01 & 0.2 \\
\hline Clindamycin & 01 & 0.2 \\
\hline Doxycycline & 01 & 0.2 \\
\hline Tab. Cefepime & 01 & 0.2 \\
\hline Inj. Linezolid & 01 & 0.2 \\
\hline Isoniazid & 01 & 0.2 \\
\hline Itraconazole & 01 & 0.2 \\
\hline Metronidazole & 01 & 0.2 \\
\hline Moxifloxacin & 01 & 0.2 \\
\hline $\begin{array}{l}\text { Tab. Cefiximelnj. } \\
\text { Ceftriaxone }\end{array}$ & 01 & 0.2 \\
\hline Tab. Ceftriaxone & 01 & 0.2 \\
\hline Vancomycin & 01 & 0.2 \\
\hline Total & 542 & 100.0 \\
\hline
\end{tabular}




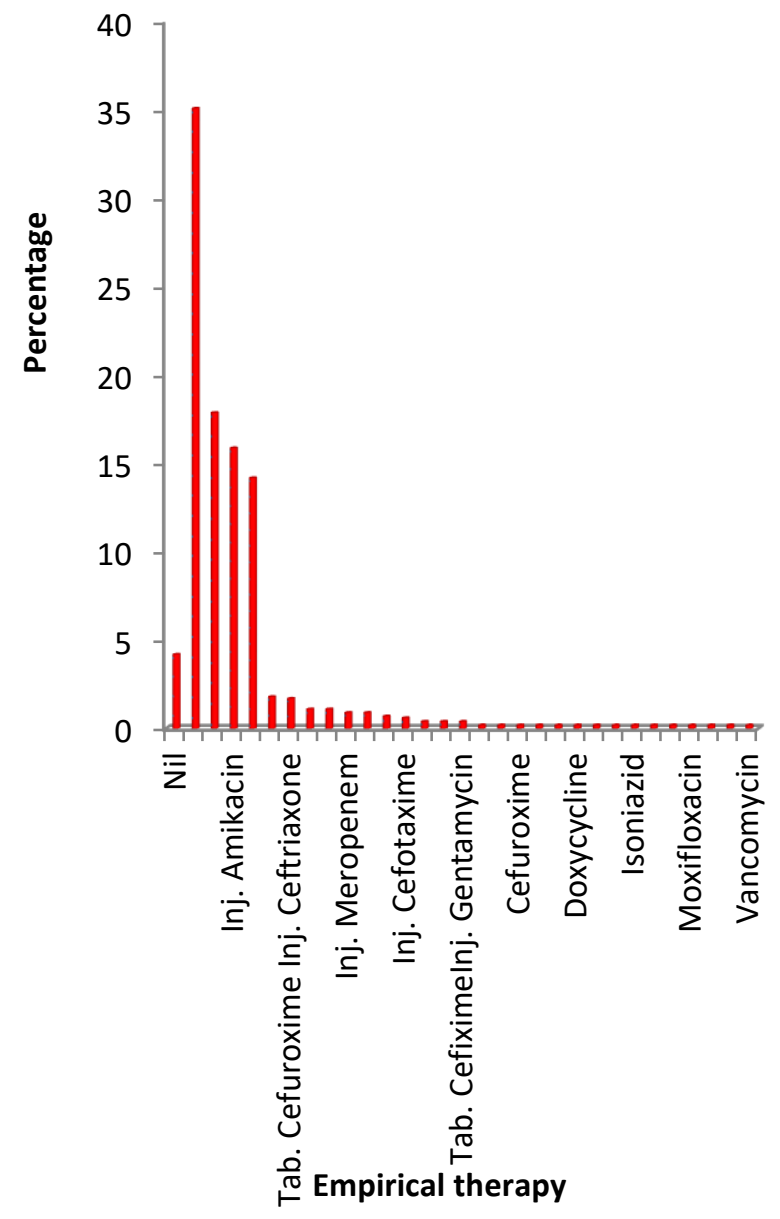

Figure 7: Empirical therapy

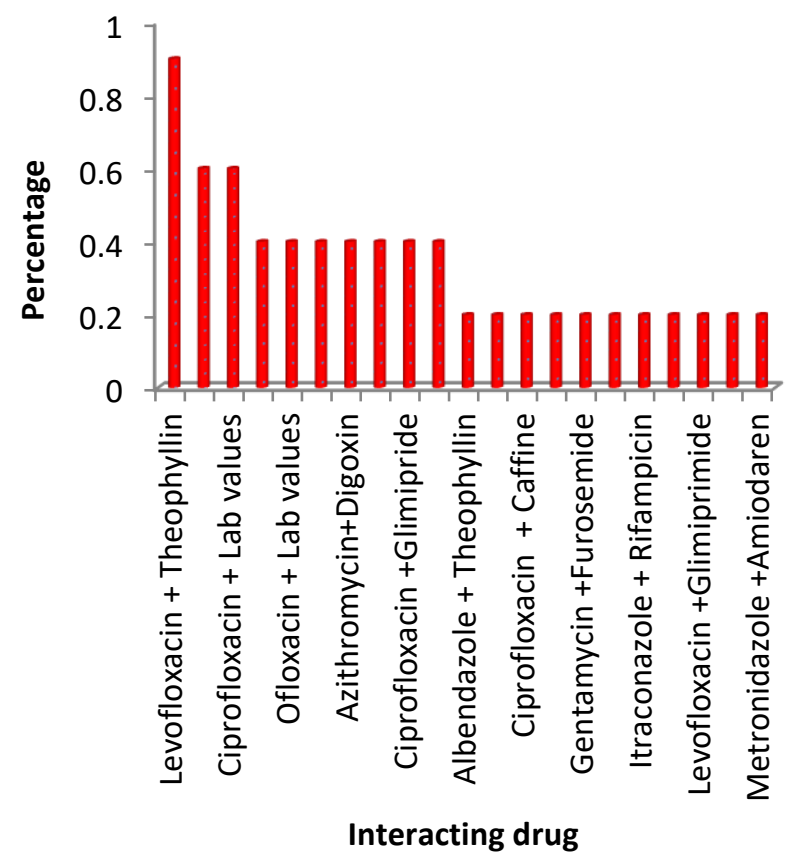

Figure 8: Interacting Drug-Frequency distribution of patients studied
Table 9: Interacting Drug-Frequency distribution of patients studied

\begin{tabular}{|c|c|c|}
\hline Interacting drug & $\begin{array}{c}\text { No. of } \\
\text { patients } \\
(n=542)\end{array}$ & $\begin{array}{c}\text { Percentage } \\
\%\end{array}$ \\
\hline No & 506 & 93.4 \\
\hline Yes & 36 & 6.8 \\
\hline $\begin{array}{l}\text { Levofloxacin + } \\
\text { Theophylline }\end{array}$ & 05 & 0.9 \\
\hline - Cefotaxime + Lab values & 03 & 0.6 \\
\hline - Ciprofloxacin + Lab values & 03 & 0.6 \\
\hline - Ciprofloxacin +Insulin & 02 & 0.4 \\
\hline - Ofloxacin + Lab values & 02 & 0.4 \\
\hline - Azithromycin+Atorvastatin & 02 & 0.4 \\
\hline - Azithromycin+Digoxin & 02 & 0.4 \\
\hline - $\quad$ Cefixime + Lab values & 02 & 0.4 \\
\hline - Ciprofloxacin +Glimepiride & 02 & 0.4 \\
\hline $\begin{array}{l}\text { - Metronidazole + Lab } \\
\text { values }\end{array}$ & 02 & 0.4 \\
\hline $\begin{array}{l}\text { - Albendazole + } \\
\text { Theophylline }\end{array}$ & 01 & 0.2 \\
\hline - Amoxicillin + Lab values & 01 & 0.2 \\
\hline - Ciprofloxacin +Caffeine & 01 & 0.2 \\
\hline - Ciprofloxacin +Sucralfate & 01 & 0.2 \\
\hline - Gentamycin +Furosemide & 01 & 0.2 \\
\hline - Itraconazole + Isoniazid & 01 & 0.2 \\
\hline - Itraconazole + Rifampicin & 01 & 0.2 \\
\hline - Levofloxacin + Insulin & 01 & 0.2 \\
\hline - Levofloxacin +Glimepiride & 01 & 0.2 \\
\hline - Metronidazole + Ethanol & 01 & 0.2 \\
\hline $\begin{array}{l}\text { - Metronidazole } \\
+ \text { Amiodaron }\end{array}$ & 01 & 0.2 \\
\hline
\end{tabular}

Table 09 shows the frequency of various drug intractions occurred in the study population. Out of 542, 36 (93.4\%) of the patients encountered drug interactions. Of these, Levofloxacin + Theophylline interaction was found in 05 (0.9\%) patients, Cefotaxime + Lab values and Ciprofloxacin + Lab values interactions each were identified in 03 (0.6\%). Ciprofloxacin +Insulin, Ofloxacin + Lab values, Azithromycin+Atorvastatin, Azithromycin+Digoxin, Cefixime + Lab values, Ciprofloxacin +Glimepiride and Metronidazole + Lab values interaction each were found in $02(0.4 \%)$ patients while Albendazole + Theophylline, Amoxicillin + Lab values, Ciprofloxacin + Caffeine, Ciprofloxacin +Sucralfate, Gentamycin +Furosemide, Itraconazole + Isoniazid, Itraconazole + Rifampicin, Levofloxacin + Insulin, Levofloxacin +Glimepiride, Metronidazole + Ethanol and Metronidazole +Amiodaron interaction each were only identified in 01 (0.2\%) patient. 
Table 10: Type of drug Interaction

\begin{tabular}{|c|c|c|}
\hline Type of drug Interaction & $\begin{array}{l}\text { No. of patients } \\
\qquad(n=542)\end{array}$ & $\begin{array}{c}\text { Percentage } \\
\%\end{array}$ \\
\hline No & 506 & 93.4 \\
\hline Yes & 36 & 6.6 \\
\hline - Drug - Lab Interaction & 19 & 3.5 \\
\hline - Drug - Drug Interaction & 15 & 2.8 \\
\hline $\begin{array}{lll}\text { - Drug - } & \text { Disease } \\
\text { Interaction } & \end{array}$ & 01 & 0.2 \\
\hline - Drug - Food Interaction & 01 & 0.2 \\
\hline
\end{tabular}
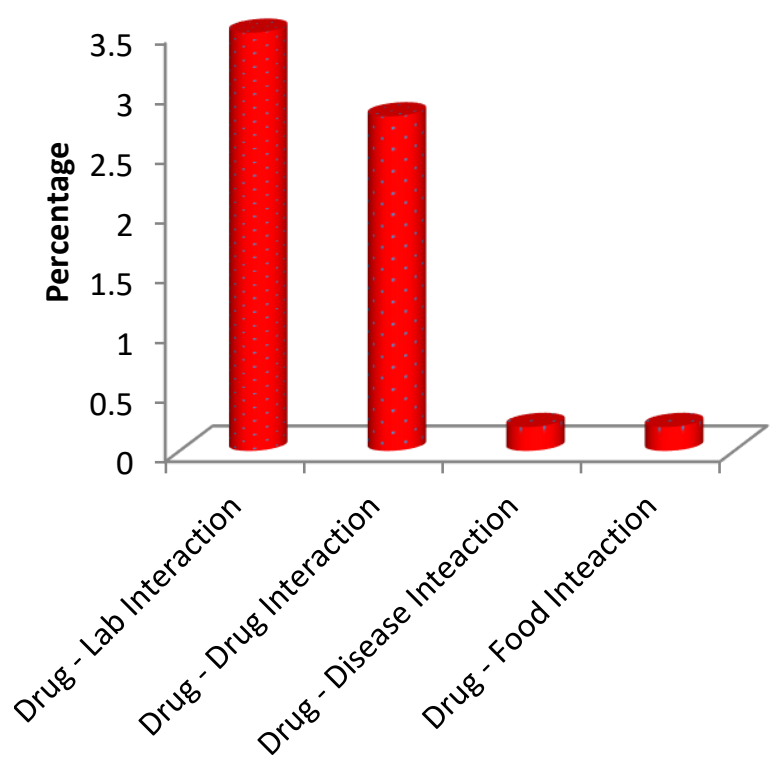

Type of drug Interaction

Figure 9: Type of drug Interaction

Frequency of types of drug interactions identified in the study population is shown in Table 10. Among 542 patients, 506 (93.4\%) had no drug interactions and only 36 (6.6\%) encountered drug interaction. Of these 36 drug interactions, 19 (3.5\%) were drug-laboratory interactions, $15(2.8 \%)$ were drug- drug interactions and 01 (0.2\%) was drug-disease and drug-food interaction each

Table 11: Severity-Frequency distribution of patients studied

\begin{tabular}{|l|c|c|}
\hline \multicolumn{1}{|c|}{ Severity } & $\begin{array}{c}\text { No. of patients } \\
(\mathbf{n = 5 4 2 )}\end{array}$ & Percentage \% \\
\hline No & 506 & 93.4 \\
\hline Yes & 36 & 6.6 \\
\hline - Major & 19 & 3.5 \\
\hline - Moderate & 10 & 1.8 \\
\hline - Minor & 07 & 1.3 \\
\hline
\end{tabular}

Table 11 shows the distribution of severity of drug interaction in the study population. Out of 542 patients, $506(93.4 \%)$ had no encounter of drug interactions and only $36(6.6 \%)$ had encountered drug ineractions. Of this 36,19 (3.5\%) were major drug ineractions, 10 (1.8\%) were moderate and $07(1.3 \%)$ were minor drug ineractions

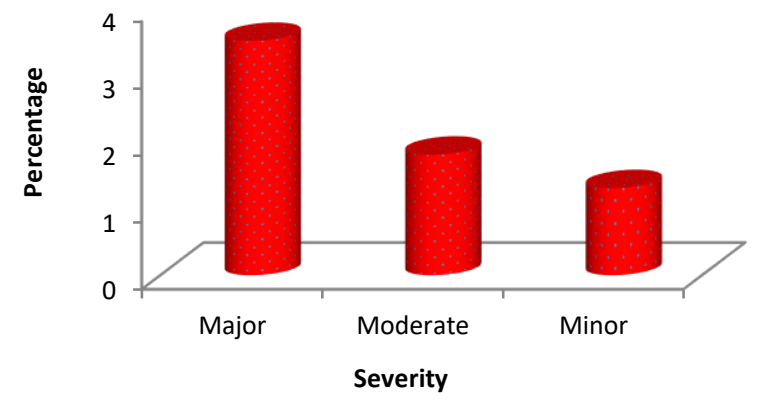

Figure 10: Severity-Frequency distribution of patients studied

Table 12: Onset-Frequency distribution of patients studied

\begin{tabular}{|c|c|c|}
\hline Onset & No. of patients $(\mathbf{n = 5 4 2 )}$ & Percentage \% \\
\hline No & 506 & 93.4 \\
\hline Yes & 36 & 6.6 \\
\hline - Rapid & 14 & 2.6 \\
\hline - Delayed & 13 & 2.4 \\
\hline - Unspecified & 09 & 1.7 \\
\hline
\end{tabular}

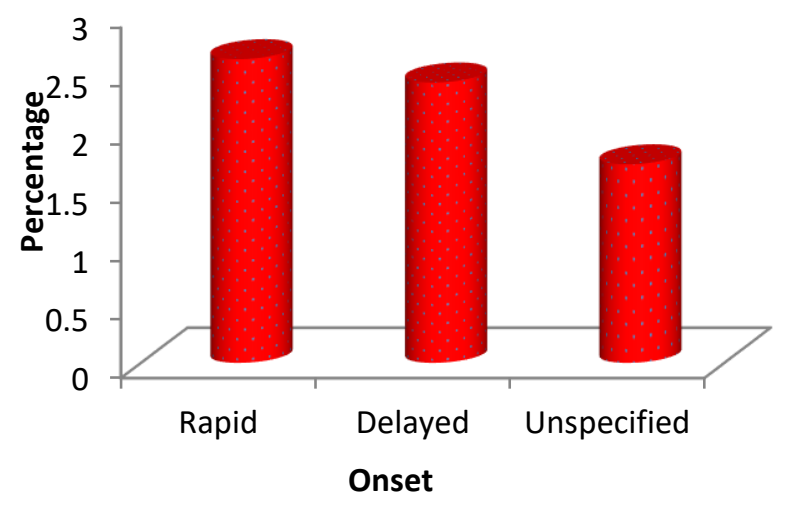

Figure 11: Onset-Frequency distribution of patients studied

Table 12: Drug classes distribution based on drug interactions

\begin{tabular}{|c|c|c|}
\hline Drug class & $\begin{array}{c}\text { Number of patients } \\
\text { with drug interactions } \\
(\mathbf{n = 3 6 )}\end{array}$ & $\begin{array}{c}\text { Percentage } \\
\mathbf{( \% )}\end{array}$ \\
\hline Fluoroquonolones & 18 & 50 \\
\hline Cephalosporins & 5 & 13.8 \\
\hline Antiamoebics & 4 & 11.1 \\
\hline Macrolides & 4 & 11.1 \\
\hline Antifungals & 2 & 05.5 \\
\hline Aminoglycosides & 1 & 02.7 \\
\hline Anthalimentic & 1 & 02.7 \\
\hline Penicillin & 1 & 02.7 \\
\hline Total & $\mathbf{3 6}$ & $\mathbf{1 0 0}$ \\
\hline
\end{tabular}


Table 12 shows the frequency of distribution of patients according to the onset of drug interactions. Out of 542 patients, 36 (6.6\%) of them encountered drug interactions. Rapid onset was seen in 14 (2.6\%) patients, Delayed onset was observed in $13(2.4 \%)$ of the patients and09 (1.7\%) patients had unspecified onset of drug interactions.

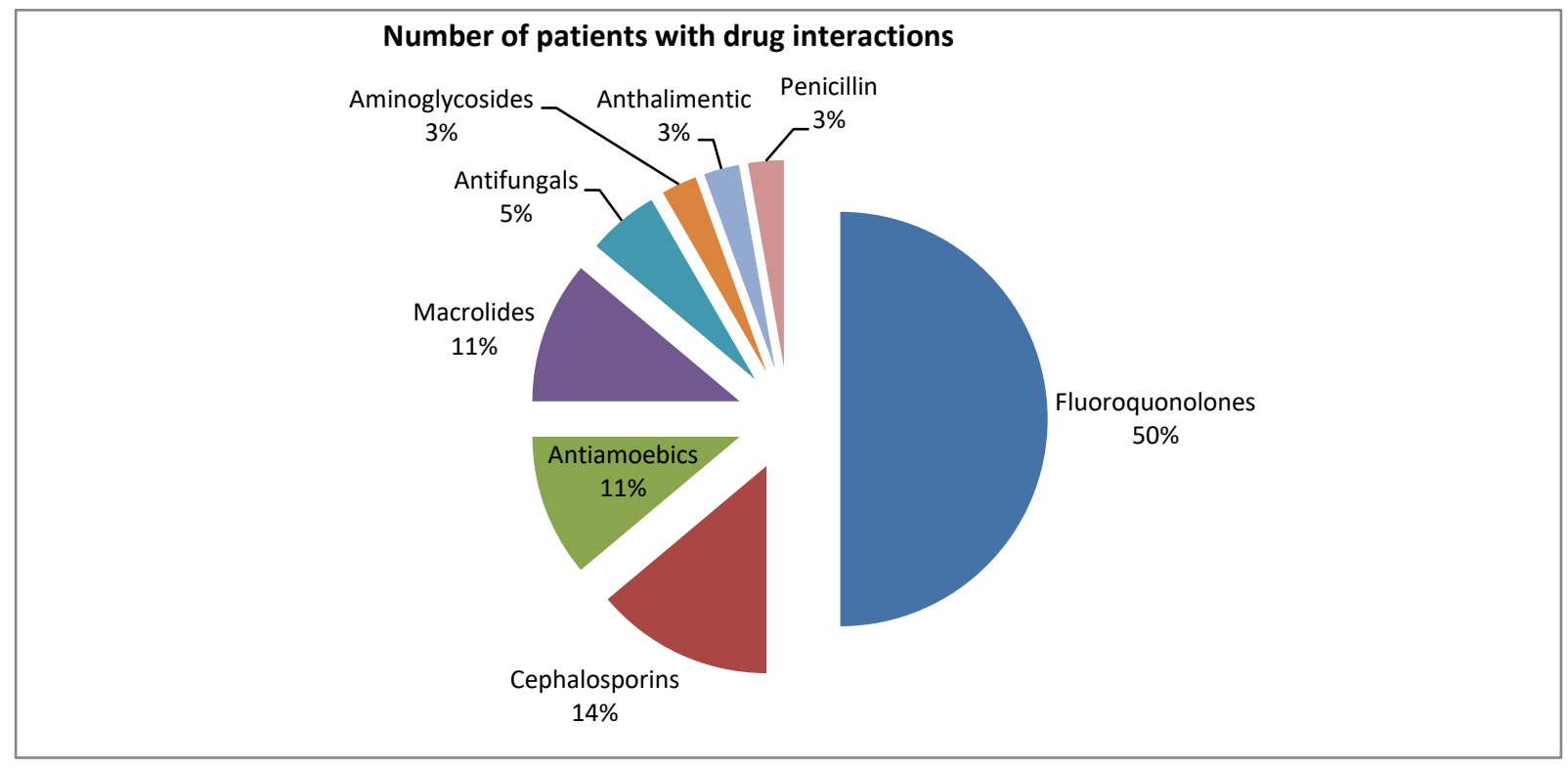

Figure 12: Drug classes distribution based on drug interactions

\section{DISCUSSION}

\section{Patients distributed based on the Gender distribution}

As shown in Table No. 01 in the current study, out of 542 patients, 325 were males and 217 were females, with $60 \%$ and $40 \%$, respectively. Similar findings were found in a study conducted by Scott T. Micek on "Empiric combination therapy associated with improved outcome against sepsis". The number of male and female patients was almost the same. However, there were slightly more male $(60 \%)$ than female $(40 \%)$ patients. This shows that gender influences the prevalence of sepsis and that males are highly prone to developing systemic infections when compared to females.

\section{Patients distributed based on the Age}

As shown in table No. 02, in the current study, the involvement of patients was across various age groups, and it was found that the maximum number of participants was observed in the age group of 61-70, with 132 (24.4\%) compared to the age group in which the lowest number of participants was seen in the age group of 18-20 years. Similar findings were found in a study conducted by Scott T. Weiss on "sepsis prevalence outcome and therapies study". This shows that the prevalence of sepsis is high in the geriatric age group.

\section{Patients distributed based on the Department}

Table No. 03 showed that, out of 542 patients in the medicine department, $416(76.7 \%)$ were found to be more patients. There were fewer patients in Urology 80 (14.8\%). More in the male medicine department due to improper medications and smokers because lack of services in the healthcare professionals and unhygienic conditions. We observed in table No. 03. A related study was conducted by Almeida S M de, Gama C S, and Akamine $\mathrm{N}$.

\section{Patients distributed based on the culture sensitivity test}

As shown in table No. 04, out of 542 patients evaluated for causative organisms, it was found that the percentage and order of various micro-organisms isolated as Neisseria meningitides 20 (3.7\%) and a lesser number of organisms were found in K. Pneumonia 01 and Streptococcus 01 $(0.2 \%)$, respectively. A similar finding was found in a study conducted by Ana Diaz-Martin on antibiotic prescription patterns in empiric therapy: a combination of antimicrobials with different mechanisms of action reduced the mortality rate in the study.

\section{Patients distributed based on the Antibiotic drug distribution}

Table No. 05 shows that among the total of 542 patients, the percentage of monotherapy usage was found to be $22.7 \%$ higher compared to other therapies. Cefuroxime $123(22.7 \%)$ was prescribed more frequently and less frequently than prescribed drugs like albendazole, ofloxacin, tazobactam, cefepime, ceftazidime, doxycycline, imipenem, norfloxacin, moxifloxacin, rifampin, cefotaxime, tigecycline, tobramycin, and vancomycin 01 $(0.2 \%)$, respectively.

\section{Antimicrobial agents distribution}

Table No. 06 shows that, Cefuroxime is a cephalosporin 3rd generation drug that was prescribed more in the antimicrobialagents distribution compared to anthelmintics, antiprotozoal, and antitubercular agents, carbapenem antibiotic, macrolide antibiotic, and tetracycline 01 (0.2). In this study, most of the physicians 
were prescribed cephalosporin derivatives because they were effective against bacteriostatic and bactericidal action and there was less medication error. A similar study was found in the reference study conducted by Prakash Goudanavar et al. on drug use evaluation of third generation cephalosporins in a tertiary care teaching hospital.

\section{Patients distributed based on the Prophylactic therapy}

As shown in table No. 07, In prophylactic therapy, Cefuroxime 190 (35.1\%) was prescribed and least prescribed, like Amoxicillin 01 (0.2\%), Ceftazidime 01 (0.2\%), Clarithromycin, Clindamycin, 01 (0.2\%), Ciprofloxacin $01(0.2 \%)$, Isonizid 01 (0.2\%), Metronidazole 01 (0.2\%), Moxifloxacin 01 (0.2\%), Cefixime 01 (0.2\%), Cefpodoxime $01(0.2 \%)$, and Vancomycin 01 (0.2\%), so we can conclude that in prophylactic therapy, Cephalosporinlike $3^{\text {rd }}$-generation drugs were more effective in infectious diseases because, based on this therapy, most of the patients also recovered.

\section{Patients distributed based on the Empirical therapy}

Table No. 08 shows that, inEmpirical therapy more commonly prescribed drug is Cefoperazone + sulbactam 267 (49.3\%), and less like Amoxicillin 01 (0.2\%), Ceftazidime 01 (0.2\%), Clarithromycin, Clindamycin, 01 $(0.2 \%)$, Isoniazid $01(0.2 \%)$, Metronidazole 01 (0.2\%), Moxifloxacin 01 (0.2\%), Cefpodoxime 01 (0.2\%), Vancomycin $01(0.2 \%)$, Cefepime $01(0.2 \%)$, Linezolid 01 (0.2\%), Clarithromycin $01(0.2 \%)$, , Doxycycline 01 (0.2\%), here based on the patients evidence based on therapy most of patients did not changed the therapy after they got laboratory report also so now we can conclude our physicians were provided the quality of life to the patients.

\section{Patients distributed based on the interacting drug frequency distribution}

Table No. 9 shows that 36 patients out of 542 had drug interactions; quinoline derivatives, such as Ciprofloxacin, typically have a higher number of drug interactions.

\section{Patients distributed based on the Type of drug interactions}

Table No. 10 shows that among 542 data points, 36 (6.6\%) observed drug interactions in Drug-Lab Interaction 19 (3.5\%), Drug-Drug Interaction 15 (2.8\%), Drug-Disease Interaction $01(0.2 \%)$, and Drug-Food Interaction 01 $(0.2 \%)$. Drug-lab interactions were more common because of the unavailability of the therapeutic drug monitoring process. One more thing may be due to chemicals or laboratory instruments, and also potential drug-drug interactions have been seen because of multiple diseases and multiple drugs. A similar study conducted by Ray WA, Murray KT, Meredith S, Narasimhulu SS, Hall K, Stein $\mathrm{CM}$, concluded that the concurrent use of erythromycin and strong inhibitors of CYP3A should be avoided.

\section{Patients distributed based on the Severity of drug} interactions

Table No. 11 showed that out of 36 (6.6\%) drug interactions, 19 (3.5\%) were moderate drug interactions, $10(1.8 \%)$ were minor drug interactions, and 07 (1.3\%). Related studies were conducted. This study states that prescription data may be useful in quality improvement programmes to identify groups of patients and practitioners at increased risk of drug interactions,Anna $C$, Sapounidis I, Pavlido G, Zoumpouridou E, Karakousis VA, Spanakis M. et al. This study concluded that an appropriate surveillance system for monitoring due to such interactions should be complemented, and physicians should be more aware of potentially harmful DDIs. Pharmacists can contribute to the detection and prevention of drug-related injuries, especially meaningful DDIs that pose a potential risk to patient safety.

\section{Patients distributed based on the Onset of drug interactions}

Table No. 12, shows that out of 36 (6.6\%) drug interactions observed, the rapid onset of action was 14 (2.6\%), the moderate onset of action was $13(2.4 \%)$, and the minor onset of action was 09 (1.7\%). Of the drug interactions observed, it was seen that $14(36.8 \%)$ of the interactions were rapid onset in nature. This implies that even if there was an interaction occurring during the concomitant administration, it may not manifest itself immediately, and if these drugs were to be continued for the patients on an outpatient basis, this could potentially lead to decreased efficacy of drugs, leading to therapeutic failures, potential adverse events, etc. These findings are like those conducted by Doubova SV, Morales HV, Arreola LDPT, and Ortega MS. This study stated that there was a high frequency of prescription of drugs with potential drug interactions. To lower the frequency of potential interactions, it could be necessary to make a careful selection of therapeutic alternatives. Another study conducted by Jeannette E. stated that computerized DDI alerts may be a useful tool to prevent adverse drug events within hospitals but may also result in alert fatigue.

\section{CONCLUSION}

In the study of prescribing patterns for antimicrobials, they need to be monitored, carefully evaluated, and, if necessary, suggested modifications in prescribing patterns so as to make the treatment rational and cost-effective.

Rational prescribing can be achieved by practicing evidence-based medicine. Since the pharmacist is often the final link between the prescribed medication and the patient, better interaction between pharmacists and patients can lead to better patient knowledge about drug use and compliance with therapy. It is an area in which a pharmacist's expertise is valued by other health professionals and where a pharmacist's knowledge of pharmacology can be recognized and appreciated. 
Male patients were found more often in our study because we knew that gender influences the prevalence of sepsis and that males are highly prone to developing systemic infections when compared to females. The incidence rate was mainly observed in the elderly male population due to improper monitoring of service cases, misuse or improper use of presented medication by the patients, and a lack of immunity and sanitization.

The study found that Neisseria meningitidis was the most predominant organism. Gram-negative agents are the most common causes of meningitis and sepsis. It was also found that cephalosporins were most commonly used and penicillins were the second most commonly used drugs, for the treatment of infectious diseases. Resistance to this drug is increasing, contributing to the greater use of fluoroquinolones. However, widespread empirical use of fluoroquinolones might also promote microbial resistance to the fluoroquinolone group of drugs. Hence, fluoroquinolones should not be considered first-line therapy. Some other serious infections can be restored with fluroquinolones. Most physicians prescribe drugs based on the characteristics of the disease and the patient. But culture and sensitivity tests should be done to know and understand the existing resistance pattern.

Our findings indicate an urgent need for the establishment of proper guidelines, dissemination of information to practitioners, and supervision of antibiotic usage in lowincome countries like India. Irrational and unnecessary drug use can be expensive and harmful, leading to resistance. An antimicrobial prescription varies by age and gender. Clinically and economically, inappropriate prescribing in many forms, including inappropriate and irrational use of antibiotics, constitutes a major health problem.
Acknowledgement: Dr. K.P. Suresh, Ph.D for reviewing methodology and results. Niharika S, Ashika R, and Swathi Gupta for creation of Tables, Listing and Graphs (TLG) and Statistical Analysis Reporting(SAR) and (Biostatistics)

\section{REFERENCES}

1. Bernard Rosner, Fundamentals of Biostatistics, $5^{\text {th }}$ Edition, Duxbury, page 80-240

2. IBM Corp. Released 2013. IBM SPSS Statistics for Windows, Version 22.0. Armonk, 2000; NY: IBM Corp

3. Robert H Riffenburg, Statistics in Medicine, second edition, Academic press. 2005; 85-125.

4. R Core Team (2013). R: A language and environment for statistical computing. $\mathrm{R}$ Foundation for Statistical Computing, Vienna, Austria

5. Sunder Rao P S S, Richard J: An Introduction to Biostatistics, A manual for students in health sciences, New Delhi: Prentice hall of India. 2006; $4^{\text {th }}$ edition: 86-160

6. Suresh K.P. and Chandrasekhar S. Sample Size estimation and Power analysis for Clinical research studies. Journal Human Reproduction Science, 2012; 5(1): 7-13

7. Sacristén JA, Soto J. Drug utilisation studies as tools in health economics. Pharmacoeconomics. 1994 Apr 1; 5(4): 299-312.

8. Book: Mayo Clinic Family Health Book, 5th Edition

9. Ryan KJ, Ray CG, eds. (2004). Sherris Medical Microbiology (4th ed.). McGraw Hill. ISBN 978-0-8385-8529-0.

10. Chambers HF. Antimicrobial agents. In: Hardman JG, Limbird LE, editor. General principles of antimicrobial therapy. The pharmacological basis of therapeutics. 10th ed. New York: McGraw-Hill; 2001. p. 1143-52.

11. Manual M. Medical information. 2nd home ed. America: Merch research laboratories; 2003.

Source of Support: The author(s) received no financial support for the research, authorship, and/or publication of this article.

Conflict of Interest: The author(s) declared no potential conflicts of interest with respect to the research, authorship, and/or publication of this article.

For any question relates to this article, please reach us at: editor@globalresearchonline.net

New manuscripts for publication can be submitted at: submit@globalresearchonline.net and submit_ijpsrr@rediffmail.com 